\title{
External and Internal Summer Atmospheric Variability in the Western North Pacific and East Asia
}

\author{
Riyu LU \\ Institute of Atmospheric Physics, Chinese Academy of Sciences, Beijing, China \\ Ying LI \\ Institute of Atmospheric Physics, Chinese Academy of Sciences, Beijing, China Graduate School, \\ Chinese Academy of Sciences, Beijing, China \\ and
}

Buwen DONG

NCAS Centre for Global Atmospheric Modelling, Department of Meteorology, University of Reading, Reading, United Kingdom

(Manuscript received 30 April 2005, in final form 5 January 2006)

\begin{abstract}
The interannual variation of summer climate in the western North Pacific and East Asia (WNP/EA) has been investigated in this study using an experiment forced by global observed sea surface temperatures (SSTs). The ensemble integrations enable us to separate externally forced variability from internal variability. It is found that the lower-tropospheric circulation anomaly over the WNP is dominated by the external variability forced by SSTs, while the anomaly of the East Asian jet (EAJ), is dominated by the atmospheric internal variability. The external variability in the WNP/EA sector is mainly reflected by the first leading empirical orthogonal function (EOF) mode of lower-tropospheric zonal wind, and partially by the second mode. The first mode is characterized by a cyclonic/anticyclonic circulation anomaly over the tropical WNP, reflecting changes in the WNP subtropical high. This mode is associated with precipitation and SST anomalies in the tropics. The second mode is characterized by a wave-like pattern of zonal wind in the meridional direction, with zonally-oriented cells over the WNP. This second mode is associated with very weak SST anomalies, and more like a mode of the internal variability. The internal mode is found to be well organized in the WNP/EA sector. The features associated with this mode include the meridional displacement, and intensity variation of EAJ, and precipitation anomaly over the WNP.
\end{abstract}

\section{Introduction}

There is a strong linkage in the meridional direction among the climatic factors in the

Corresponding author: Riyu Lu, Institute of Atmospheric Physics, Chinese Academy of Sciences, PO Box 9804, Beijing 100029, China.

E-mail: lr@mail.iap.ac.cn

(C) 2006, Meteorological Society of Japan western North Pacific, and East Asia (WNP/ EA) (Nitta 1987; Tsuyuki and Kurihara 1989; Wang et al. 2001; Lu 2004). Therefore, the climate in the East Asian countries is affected by both the tropical processes and mid-latitude disturbances. The tropical processes in the western Pacific are induced, to a large extent by the sea surface temperatures (SSTs), while the mid-latitude disturbances are dominated 
by internal variability (e.g., Kang et al. 2004). Thus, both external and internal variabilities can significantly affect the East Asian climate.

The influence of the tropical SST anomalies, particularly of those related to the El NiñoSouthern Oscillation (ENSO), on the summer atmospheric circulation and rainfall over the WNP/EA has been extensively studied. Interannual variability of climate in the WNP is found to be related to the phases of ENSO (e.g., Huang and Wu 1989; Wang et al. 2000; Ailikun and Yasunari 2001; Wang and Zhang 2002; Lu 2002; Chou et al. 2003). Wang et al. (2000) proposed a mechanism that the ENSO has a delayed impact on the climate in the WNP/EA sector through a positive feedback of the in situ air-sea interaction in the WNP. Wu and Wang (2002) concluded that there is a change in this delayed affect of ENSO on the climate in the WNP/EA sector in the late 1970s. On the other hand, some studies investigated the simultaneous influence of ENSO on the summer climate in the WNP/EA sector (Zhang et al. 1996, 1999; Tanaka 1997; Wu and Wang 2000). From the results of these studies, it can be concluded that the interannual variability of climate in the WNP/EA sector is indeed linked to the ENSO, but this link is modest and complex.

In addition, the East Asian summer climate is affected more significantly by mid-latitude conditions. For instance, it is found that on the interannual timescale, a zonally oriented teleconnection pattern can be identified along the Asian upper-tropospheric jet, and is linked to the climate anomalies in East Asia (Krishnan and Sugi 2001; Lu et al. 2002; Enomoto 2004; Wakabayashi and Kawamura 2004). Lu et al. (2002) found that this teleconnection pattern is geographically stationary, which can be explained by an analysis on barotropic kinetic energy conversion of Sato and Takahashi (2003). The extratropical atmospheric anomalies are more controlled by the internal atmospheric processes (e.g., Wang et al. 1997; Kang et al. 2004). The summer rainfall belt in East Asia (hereafter the Meiyu belt for abbreviation), is located at $25^{\circ}-40^{\circ} \mathrm{N}$. Thus, it may be implied that the internal variability would play a considerable role in influencing the climate in East Asia.

A lower-tropospheric cyclonic/anticyclonic cir- culation anomaly over the subtropical WNP is connected with the summer rainfall anomalies in East Asia and in the tropical WNP (Wang et al. 2001). A zonal displacement of the subtropical high over the WNP closely corresponds to anomalous convection over the tropical WNP ( $\mathrm{Lu}$ 2001). A westward extended subtropical high is associated with a lower-tropospheric anticyclonic anomaly over the subtropical WNP, which results from an atmospheric Rossby wave response to suppressed convection over the Philippine Sea (Lu and Dong 2001).

The EAJ is also intimately related to rainfall anomalies in East Asia in summer. Studies by Liang and Wang (1998), Lau et al. (2000) and $\mathrm{Lu}$ (2004) showed that a poleward (equatorward) shift of the EAJ is significantly related to suppressed (enhanced) convection along the Meiyu belt. Lau et al. (2000) used the meridional displacement of the EAJ to quantitatively measure the interannual variability in the East-Southeast Asian monsoon. Lin and $\mathrm{Lu}$ (2005) performed an empirical orthogonal function (EOF) analysis on the interannual variability in $200-\mathrm{hPa}$ zonal wind over the subtropical WNP and East Asia, and found that the first and second leading modes reflect the EAJ's meridional displacement and intensity variation, respectively.

What are the features of the external and internal variabilities in these dominant circulation systems in the WNP/EA sector in summer? To what extent, the external and internal variabilities contribute respectively to the interannual variations of these circulation systems? These questions are essential for the predictability of the climatic variability in the WNP/ EA sector. In addition, addressing these questions is also helpful for the better understanding of the physical mechanisms responsible for the climatic variability in the WNP/EA sector. In this study, we address these questions by separating externally forced variability from internal variability through an ensemble of integrations, by a model forced with the global observed SSTs. Some previous studies investigated the contributions of external forcing, and internal process to climatic variability (e.g., Harzallah and Sadourny 1995; Rowell et al. 1995; Goswami 1998). However, there have been few studies on the external and internal variabilities in summer atmospheric circulation 
systems over the WNP/EA sector. The experimental design and analysis approach, are described in section 2 . We analyze the variabilities of lower-tropospheric circulation, and uppertropospheric circulation over the WNP/EA sector in sections 3 and 4 , respectively. Section 5 is devoted to a summary.

\section{Experimental design}

The numerical model used in this study is the Met Office Hadley Centre atmospheric general circulation model, known as HadAM3. The model uses a $2.5^{\circ}$ latitude by $3.75^{\circ}$ longitude grid, and 19 model levels. It includes the new land surface scheme developed by Cox et al. (1999). This new land surface scheme includes a representation of the freezing and melting of soil moisture, leading to better simulations of surface temperatures, and a new formulation of evaporation, which includes the dependence of stomatal resistance to temperature, vapour pressure deficit and $\mathrm{CO}_{2}$. A detailed description of the model formulation, and its performance, is documented in Pope et al. (2000).

The experiment was conducted over the period 1 December 1985 to 31 August 2000, with global observed SSTs and sea ice extent, as described by Reynolds et al. (2002). In order to separate externally forced variability from internal variability, an ensemble of ten integrations was performed with slightly different initial states. The initial conditions were taken from 10 consecutive days of a spin-up integration. In this study, the simulated interannual variability is separated into an external component and an internal component, with a similar approach of Rowell et al. (1995). That is, the external variability is defined as the ensemble mean, and the internal variability is defined as the deviations from the ensemble mean. The only assumptions required are that the internal variability is the same for each year, and that the effect of altering the initial atmospheric conditions has a purely random impact on the simulated seasonal anomalies. For the details of calculating method, refer to Rowell et al. (1995).

The observed data were used in this study to evaluate the simulated results. They include the monthly precipitation data from 1979 to 2003, derived by the Climate Prediction Center (CPC) Merged Analysis of Precipitation (CMAP;
Xie and Arkin 1997), SST (Smith and Reynolds 2004), and monthly mean NCEP-NCAR reanalysis data from 1958 to 2003 (Kalnay et al. 1996). We used the 15-year data from 1986 to 2000 , identical to the simulation period in this study, to facilitate the comparison with the simulated results. We also used extended observation data, 1979-2003 for precipitation, and 1958-2003 for circulation and SST, to evaluate the results based on the 15-year data.

\section{Lower-tropospheric circulation and precipitation in the western North Pacific}

\section{a. Basic features in observation and simulation}

Figure 1 shows the climatological JJA-mean precipitation and $850-\mathrm{hPa}$ horizontal winds in observations and simulation. The model captures very well the basic features of both the Intertropical Convergence Zone (ITCZ), and anticyclonic circulation over the Pacific and Indian Ocean. It also reproduces the small-scale heavy precipitations in the western coast of India, the Bay of Bengal, the South China Sea and the Philippine Sea, and the meandering pattern of lower-tropospheric westerly jet over South Asia. The simulation differs slightly from observations in the WNP, showing less precipitation and weaker southwesterly in Korea and Japan, both of which may be related to each other.

Figure 2 shows the variance of JJA-mean precipitation, and $850-\mathrm{hPa}$ zonal winds in observations and simulation. The variance of interannual variation of precipitation, both for observations and external variability in the simulation (Figs. 2a and 2c), is large in the ITCZ, and resembles well the climatological means in distribution. In the tropics, the externally forced precipitation has a variance similar to the observed precipitation. The $850-\mathrm{hPa}$ zonal wind, both for observations and external variability in the simulation, exhibits a great interannual variability over a belt extending from the equatorial central Pacific to South Asia (Figs. 2b and 2d). In comparison with observations, the model simulates a stronger interannual variability over the belt, and tropical eastern North Pacific, and a weaker variability in the extratropics, which is expected since the variances of external variability are calculated 
Clim. of JJA-mean (1986-2000)
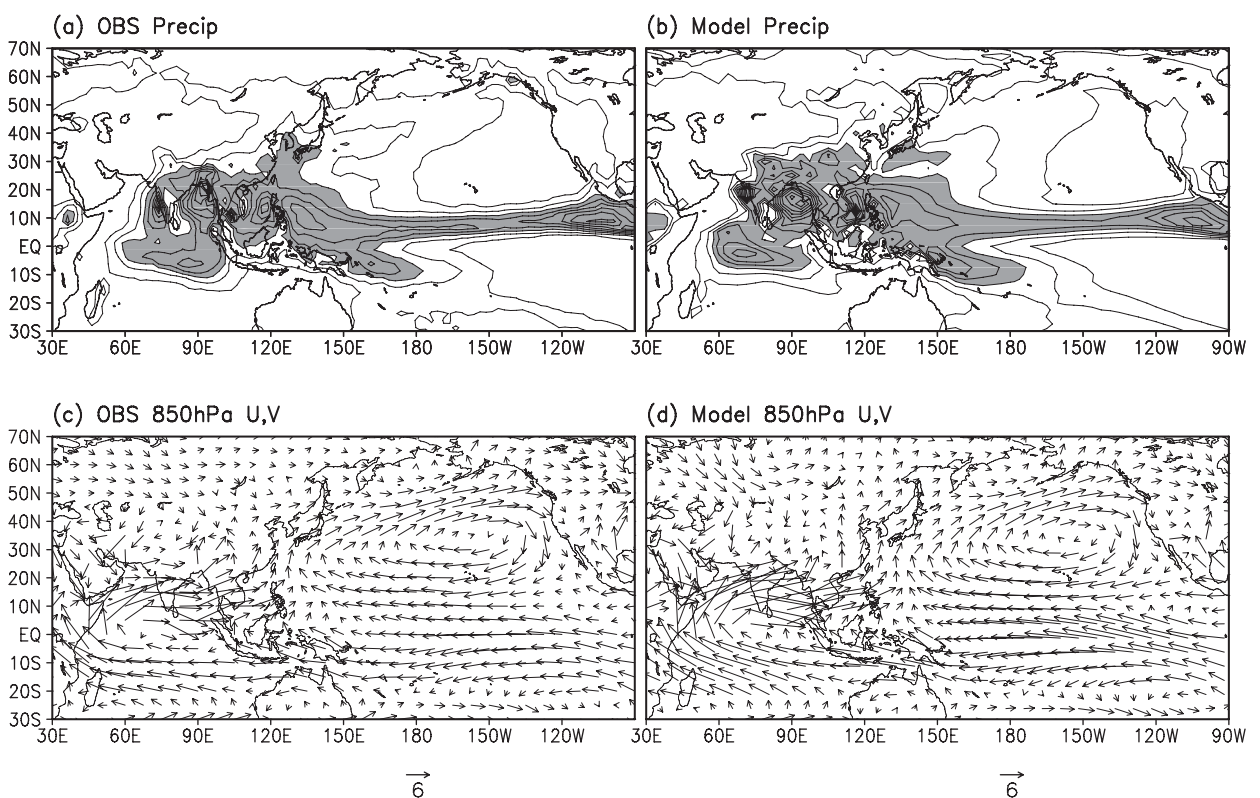

Fig. 1. JJA-mean precipitation (upper panels) and $850-\mathrm{hPa}$ horizontal winds (lower panels) in observations (left panels) and simulation (right panels), averaged over 15 years (1986-2000). Unit is $\mathrm{mm} \mathrm{d}^{-1}$ for precipitation and $\mathrm{m} \mathrm{s}^{-1}$ for wind. Contour intervals are 2 for precipitation, and values greater than 6 are shaded.

by the ensemble means, and since internal variability is generally stronger in the extratropics. The zonal wind at $850 \mathrm{hPa}$ exhibits a weak interannual variability over the Indian Ocean and South Asia than over the western Pacific, although precipitation shows comparable variability in these regions. The variances of $850-\mathrm{hPa}$ zonal wind bear no resemblance to the climatological means.

The internal variance of precipitation (Fig. $2 \mathrm{e}$ ) is large in the western coast of India, the Bay of Bengal, the South China Sea and the Philippine Sea, the tropical eastern North $\mathrm{Pa}-$ cific, and the southern Indian Ocean. In comparison with the external variance, the internal variance is relatively larger in the southern Eurasian continent, East Asia, the subtropical WNP and the central North Pacific. The internal variance of $850-\mathrm{hPa}$ zonal wind (Fig. 2f) is larger than, or comparable to, the external variance in the subtropical WNP and extratropical North Pacific. In the tropics, compared with precipitation, circulation has much smaller values of internal variance than the external variance, indicating that the latter has a higher potential predictability than the former. In summary, the internal variability of both precipitation and lower-tropospheric zonal wind is strong in the WNP, the region focused on at this section.

The ratios between the external variance, and internal variance are shown in Figs. 2g and $2 \mathrm{~h}$, as in Kang et al. (2004). The external variance is much larger in the tropical Pacific and the maritime continent, but is smaller in the extratropics, in comparison with the internal variance, for both precipitation and 850$\mathrm{hPa}$ zonal wind. Both the amplitude and distribution of ratios are in good agreement with those in Kang et al. (2004), who used a different AGCM.

\section{b. Observation and external variability}

An empirical orthogonal function (EOF) analysis was performed on the JJA-mean $850-\mathrm{hPa}$ zonal wind, to investigate the dominant features of the lower-tropospheric circulation in the WNP. The EOF analysis on JJA-mean precipitation, $850 \mathrm{hPa}$ and $200 \mathrm{hPa}$ zonal winds simulated by a member of the ensemble inte- 


\section{Variance}
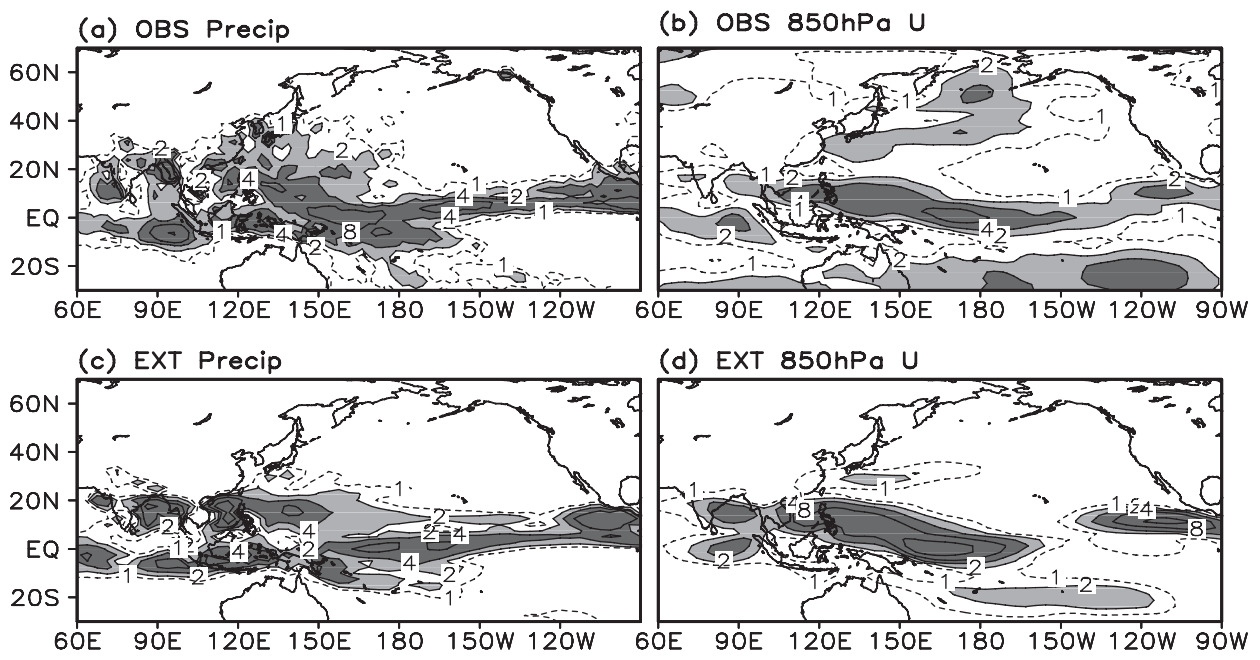

(d) EXT $850 \mathrm{hPa} U$

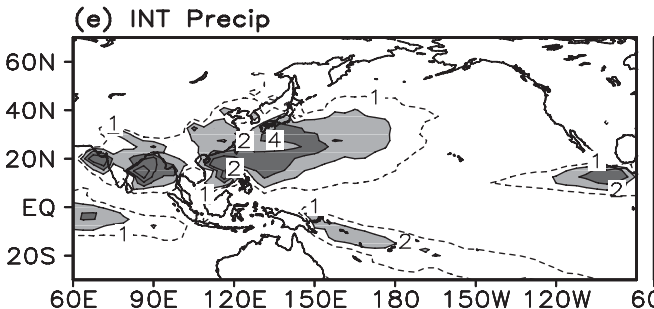

(f) INT $850 \mathrm{hPa} \mathrm{U}$

(g) EXT/INT
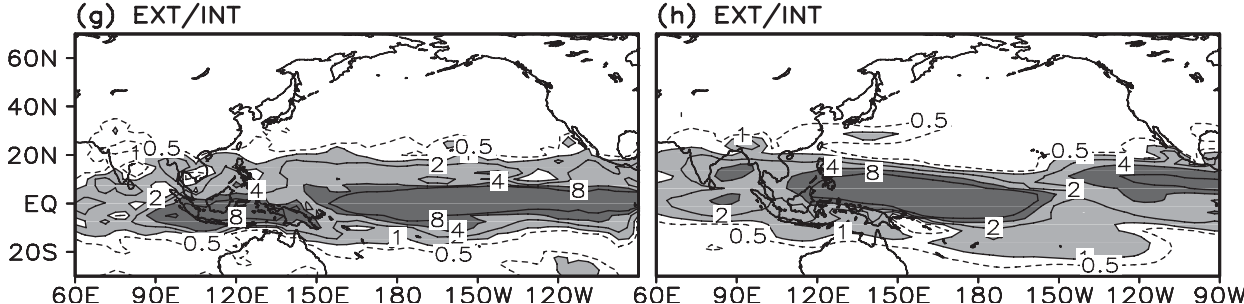

Fig. 2. Variances of JJA-mean precipitation (left panels) and 850-hPa zonal winds (right panels) for observations, external and internal variabilities (three panels from the top, respectively). The contour lines are plotted at $1,2,4,8$, and 16 . Unit is $\mathrm{mm}^{2} \mathrm{~d}^{-2}$ for precipitation variance and $\mathrm{m}^{2} \mathrm{~s}^{-2}$ for wind variance. The lowest panels present the ratios of external variance to internal variance.

gration illustrated that the structures of the first two leading modes are similar to those of observations (not shown), indicating that the model is able to simulate the two leading modes of the variability identified in observations in a satisfactory manner.

Figure 3 shows the spatial structures, and time series of the first two leading EOFs, for observations and external variability (hereafter is referred to as "observation EOFs" and "external EOFs", respectively). The observation EOF-1 is dominated by strong easterly, over a belt ex- tending from the equatorial central Pacific to South Asia, and by westerly over South China, and subtropical WNP (Fig. 3a). Its major signals appear over the tropics and subtropics. The present result of EOF-1 is consistent with the leading EOF mode from the multivariate EOF analysis of $850 \mathrm{hPa}$ wind vectors by Wang et al. (2001). Wang et al. (2001) defined a dynamic summer monsoon index to measure the interannual variability of the WNP monsoon as the difference of $850-\mathrm{hPa}$ westerlies, between the two regions $\left(100-130^{\circ} \mathrm{E}, 5-15^{\circ} \mathrm{N}\right)$ 

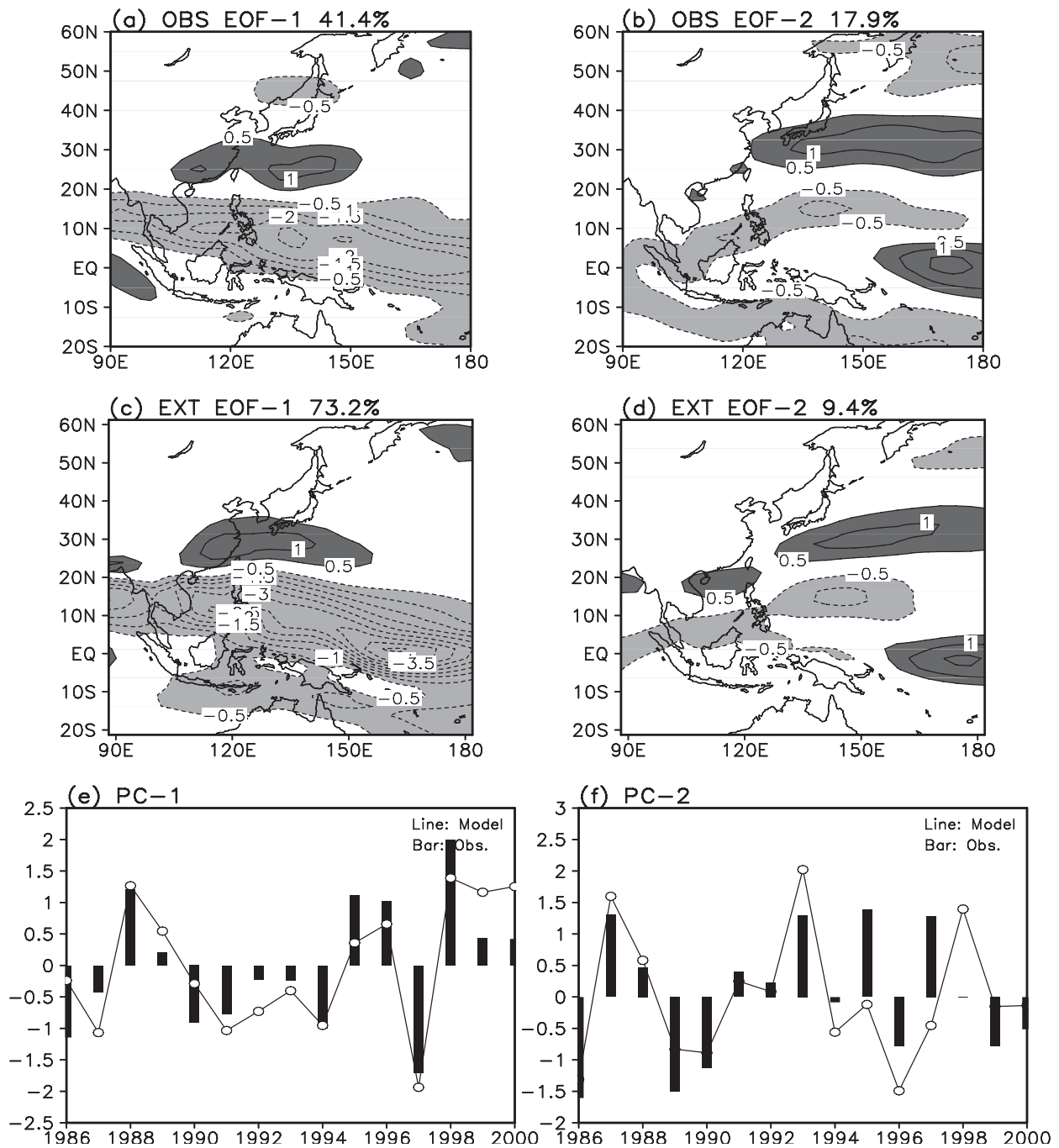

Fig. 3. Spatial patterns of dominant modes of observational (upper panels) and ensemble-mean (middle panels) 850-hPa zonal wind for EOF-1 (left panels) and EOF-2 (right panels). (e) and (f) show the variations of principal components of the first and second leading modes, respectively. In (e) and (f), the bars are for observational PCs, and the lines for external PCs. Unit is arbitrary.

and $\left(110-140^{\circ} \mathrm{E}, 20-30^{\circ} \mathrm{N}\right)$, according to their result of multivariate EOF analysis. The observation EOF-2 is characterized by the meridionally alternative appearances of east-west elongated westerly and easterly over the western Pacific (Fig. 3b). The amplitudes are nearly identical for westerly and easterly, and are not appreciably changed with the latitudes.

These two EOFs in total explain about $60 \%$ of total variance, and the first one explains over two times variance of the second one. The domain of the present EOF analysis is $\left(90^{\circ} \mathrm{E}-\right.$ $180^{\circ}, 20^{\circ} \mathrm{S}-60^{\circ} \mathrm{N}$ ), identical to the spatial scopes shown in Fig. 3. We have used substantially different domains for EOF analysis, for instance, as large as $\left(30^{\circ} \mathrm{E}-180^{\circ}, 20^{\circ} \mathrm{S}-60^{\circ} \mathrm{N}\right)$ and as small as $\left(120^{\circ} \mathrm{E}-180^{\circ}, 20^{\circ} \mathrm{S}-60^{\circ} \mathrm{N}\right)$, and found that the two leading EOFs, and their principle components (PCs), are not appreciably changed.

The external EOF-1 explains most of the total external variance $(73.2 \%)$. The spatial structure of external EOF-1 (Fig. 3c) resembles well that of observation EOF-1, except the 
Table 1. Cases chosen for composite analyses. These cases are chosen according to the extreme positive (negative) values of the principal components (PCs) of leading EOFs of JJA-mean $850-\mathrm{hPa}$ zonal wind in the WNP/EA sector.

\begin{tabular}{l|ll|ll}
\hline & \multicolumn{2}{|c|}{+} & \multicolumn{2}{c}{-} \\
\hline Observation & 1988 & 1995 & 1986 & 1990 \\
PC-1 & 1996 & 1998 & 1994 & 1997 \\
\hline Observation & 1987 & 1993 & 1986 & 1989 \\
PC-2 & 1995 & 1997 & 1990 & 1996 \\
\hline External & 1988 & 1998 & 1987 & 1991 \\
PC-1 & 1999 & 2000 & 1994 & 1997 \\
\hline External & 1987 & 1988 & 1986 & 1989 \\
PC-2 & 1993 & 1998 & 1990 & 1996 \\
\hline
\end{tabular}

southward extension, and intensification of the easterly in the tropics. Actually, the external PC-1 and observation PC-1 are significantly correlated (also see Fig. 3e), with the correlation coefficient of 0.853 (significant at $99.9 \%$ level). On the other hand, the external EOF-2 explains only $9.4 \%$ of variance. Its spatial structure (Fig. 3d) resembles somewhat the spatial structure of observation EOF-2, and the correlation coefficient between the external PC-2 and observation PC-2 is 0.675 (significant at $95 \%$ level, also see Fig. 3f).

We performed composite analyses based on the principal components of the first two leading modes, in order to illustrate the anomalies of precipitation and SST associated with these dominant circulation modes. By choosing four cases with the highest values, and four cases with the lowest values of each time series of the principal component (Table 1), we showed the composite differences.

Corresponding to the observation PC-1, there are negative precipitation anomalies in the Philippine Sea, and weak positive anomalies in East Asia (Fig. 4a). The negative precipitation anomalies in the Philippine Sea are associated with anticyclonic circulation anomalies in lower troposphere over the WNP, with tropical easterly anomalies and subtropical westerly anomalies shown in Fig. 3a. In addition, significant positive precipitation anomalies appear in the maritime continent, and negative anoma- lies appear in the equatorial western Pacific. A positive PC-1 corresponds to positive SST anomalies in the western Pacific and eastern Indian Ocean, and negative SST anomalies in the equatorial eastern Pacific (Fig. 4c).

The observation EOF-2 corresponds to significantly less precipitation in the northeast extent of the Philippine Sea, and more precipitation in East Asia (Fig. 4b). In addition, there are positive anomalies in the equatorial western and central Pacific. This pattern of precipitation anomalies is associated with positive SST anomalies in the equatorial eastern Pacific (Fig. 4d), but the composite result based on the extended period (1958-2003) of observational data, shows very weak SST anomalies (not shown).

Similarly, we performed composite analyses based on the principal components of the first two leading external modes for the model simulation. The chosen cases bear a resemblance to those based on observations, but with an appreciable distinction (Table 1). Such a resemblance is expectable, because of the high correlation between the model external, and observation modes. The precipitation and SST anomalies corresponded to the external PC-1 (Figs. 5a and 5c) are stronger and more significant than those corresponded to the observation PC-1 (Figs. 4a and 4c), and their spatial distributions are in good agreement. Both for observations and for external variability, the SST anomalies exhibit a seesaw pattern, between the equatorial eastern Pacific and the equatorial western Pacific/eastern Indian Ocean, and may induce positive precipitation anomalies in the maritime continent, and negative precipitation anomalies in the equatorial western and central Pacific. The positive precipitation anomalies in the maritime continent, in turn, may result in less rainfall in the Philippine Sea and South Asia through a local Hadley circulation anomaly, which is suggested by anomalous $200-\mathrm{hPa}$ southerly and $850-\mathrm{hPa}$ northerly (not shown).

However, the precipitation and SST anomalies associated with the external EOF-2 (Figs. $5 \mathrm{~b}$ and $5 \mathrm{~d}$ ) are relatively different from those associated with the observation EOF-2, despite some resemblances in distribution. For instance, the observation EOF-2 corresponds to the well-organized precipitation anomalies in 

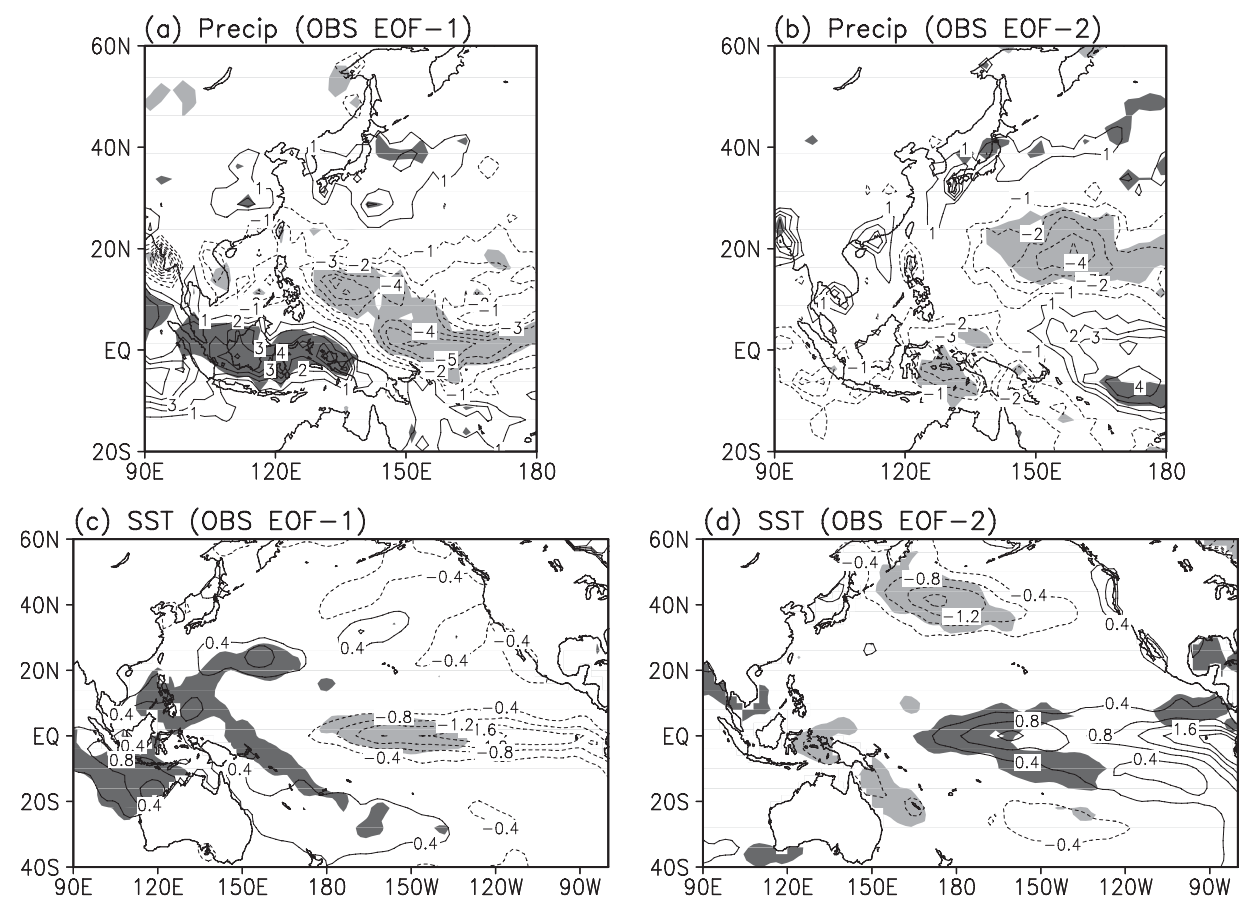

Fig. 4. Composite differences in precipitation (upper panels) and in SSTs (lower panels) based on the observational PC-1 (left panels) and PC-2 (right panels). Composite cases are shown in Table 1. Zero contours are not shown, and the unit is $\mathrm{mm} \mathrm{d}^{-1}$ for precipitation and ${ }^{\circ} \mathrm{C}$ for SST. The shading indicates the regions of $95 \%$ significance level by using a two-tailed Student's $t$-test.

the western Pacific, and SST anomalies in the equatorial eastern Pacific, but these anomalies are much weakened or disappear in the external EOF-2.

\section{c. Internal variability}

An EOF method is also applied to illustrate dominant modes of internal variability in the $850-\mathrm{hPa}$ zonal wind in the model simulation. 150 samples of internal variability are used to perform the EOF analysis. The spatial distribution of the first leading internal mode (Fig. 6a), is similar to that of the observation EOF-2 in the WNP/EA (Fig. 3b). The only difference between them is the disappearance of the positive values in and south to the equator, for the internal mode. The similarity suggests that the observation EOF-2 would be closely related to the internal mode. The difference, on the other hand, indicates that the observation EOF-2 also partially results from the external forcing, which generally plays the most dominant role in the tropics.

A linear regression is performed, based on the normalized principal component of the first leading internal mode, and the regressed precipitation is presented in Fig. 6b. The internal leading mode corresponds to significantly less precipitation in the subtropical WNP and more precipitation in East Asia, around $10^{\circ} \mathrm{N}$. The regressed precipitation is similar to that corresponded to the observation EOF-2 (Fig. 4b) in the WNP/EA. Thus, the leading mode of not only external variability, but also internal variability over the WNP and EA is associated with precipitation anomalies in the tropics.

\section{East Asian Upper-tropospheric jet stream}

The EAJ is located in the middle latitudes, with its axis approximately at $40^{\circ}-45^{\circ} \mathrm{N}$ in summer. Its higher latitudes imply a larger contribution of the internal atmospheric variability to its seasonal mean anomalies. By using an approach similar to the preceding section, the external and internal leading modes related to the EAJ are examined and compared with observations in this section. 

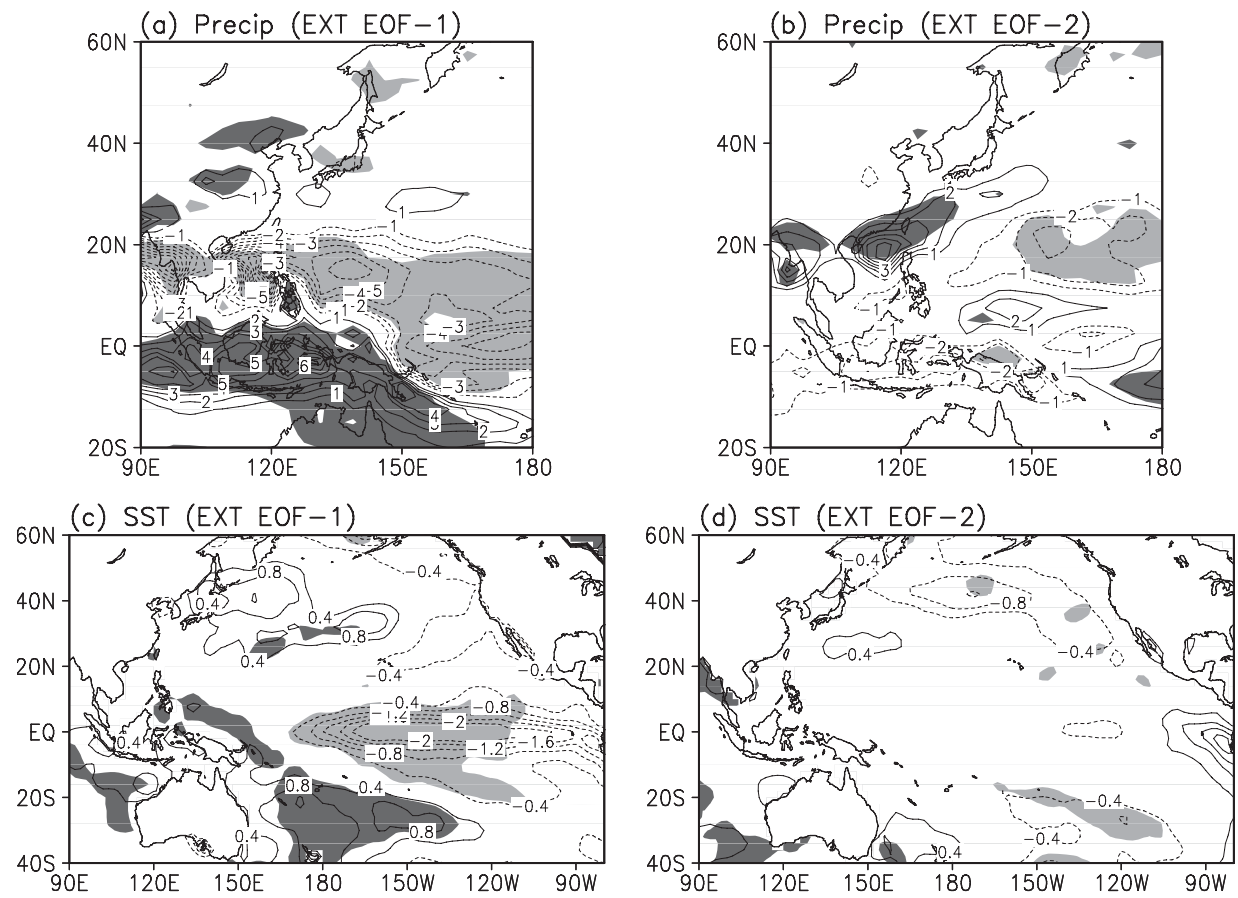

Fig. 5. Same as Fig. 4, but based on the external PC-1 and PC-2.
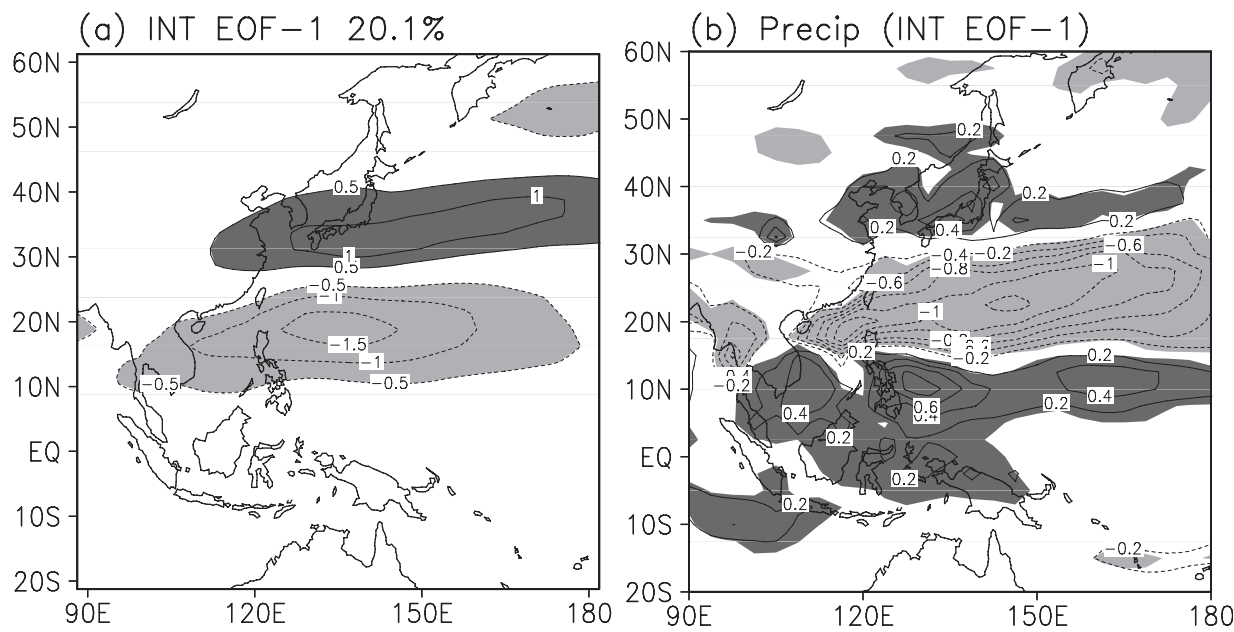

Fig. 6. Spatial patterns of the first leading mode for internal variability in JJA-mean zonal wind at $850 \mathrm{hPa}$ (a), and precipitation regressed onto the normalized principal component of the first mode for internal variability (b). Unit is $\mathrm{mm} \mathrm{d}^{-1}$ for precipitation in (b), and the shading indicates the regions of $95 \%$ significance level based on the $F$-test.

\section{a. Basic features of EAJ in observations and simulation}

The model captures well the climatological features of EAJ and Tibetan Anticyclone (Figs. $7 \mathrm{a}$ and $7 \mathrm{~b})$. It also reproduces the ridges and troughs in the mid-high latitudes over the Eurasian continent, although overestimates their intensities. The 200-hPa zonal wind for observations exhibits a great interannual variability along several zonally oriented belts over the 
(a) OBS $200 \mathrm{hPa} U, \mathrm{~V}$

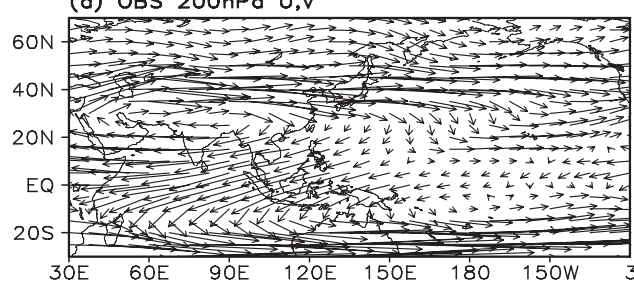

(b) Model $200 \mathrm{hPa} U, \mathrm{~V}$
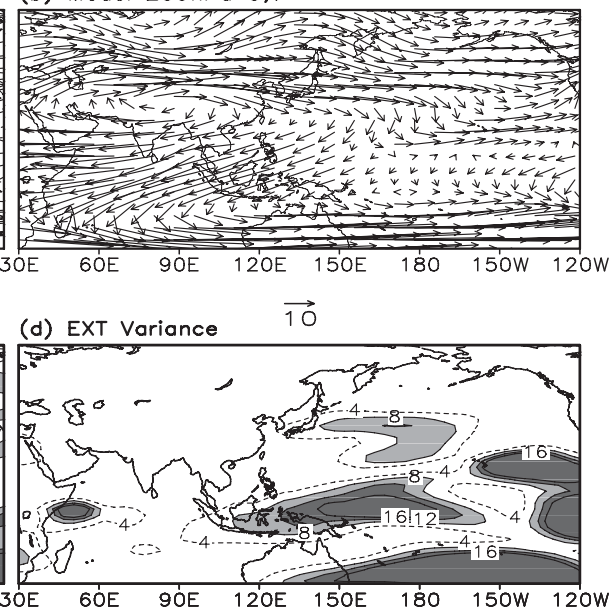

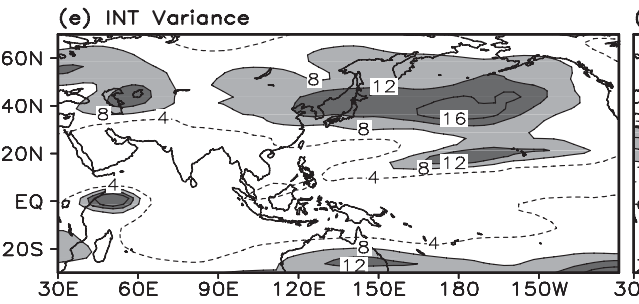

(f) EXT/INT

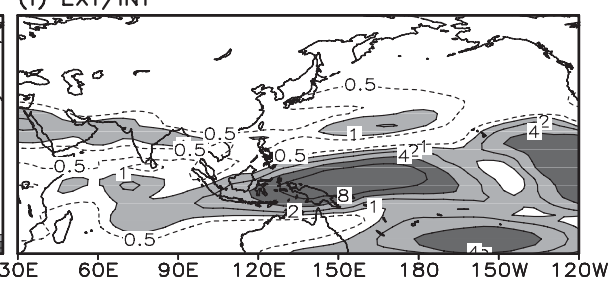

Fig. 7. Observed (a) and ensemble-mean (b) JJA-mean 200-hPa horizontal winds, averaged over 15 years (1986-2000), and year-to-year variances of 200-hPa zonal wind for observations (c), external (d) and internal variability (e). Unit is $\mathrm{m} \mathrm{s}^{-1}$ in (a) and (b), and $\mathrm{m}^{2} \mathrm{~s}^{-2}$ in (c-e). The contour lines are plotted at $4,8,12$, and 16 .

Pacific, concurred roughly with either strong westerlies or the tropical central and eastern Pacific where action centers of ENSO locate (Fig. 7c). In comparison with observations, the model simulates stronger interannual variability in the equatorial western and central Pacific as external variability. The variances of $200-$ $\mathrm{hPa}$ zonal wind show a great difference in the Northern Hemisphere mid-latitudes, between the external variability and observations. Particularly, the observed $200-\mathrm{hPa}$ zonal wind shows a great interannual variability around the EAJ, while the simulated ensemble means show a much weakened variability. This difference in the variances results from the fact that the internal variability is generally stronger in the extratropics, as shown in Fig. 7e. Actually, the internal variability is relatively greater around the Caspian Sea, and over a large region extending from East Asia eastward to the North Pacific. Over East Asia, the internal variability is much stronger than the external variability (Fig. 7f), and comparable to the variability in observations, suggesting that the internal atmospheric processes would play a crucial role in the variations of the EAJ.

\section{b. Interannual variability of EAJ in observations and simulation}

The interannual variations of the EAJ have two most dominant modes: the meridional displacement and variation in intensity (Lin and $\mathrm{Lu}$ 2005). These two dominant modes are related to the significant precipitation anomalies

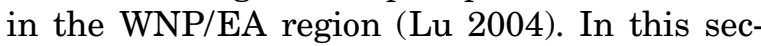
tion, an EOF analysis is performed by using the averaged $200-\mathrm{hPa}$ zonal winds over $120-$ $150^{\circ} \mathrm{E}$, since these averaged winds can well illustrate both the meridional displacement, and variation in the intensity of the EAJ. The meridional domain of EOF analysis is $0-90^{\circ} \mathrm{N}$.

Figure 8 shows the spatial structures of the first two leading EOFs of JJA-mean $200-\mathrm{hPa}$ zonal wind averaged over $120-150^{\circ} \mathrm{E}$, for obser- 

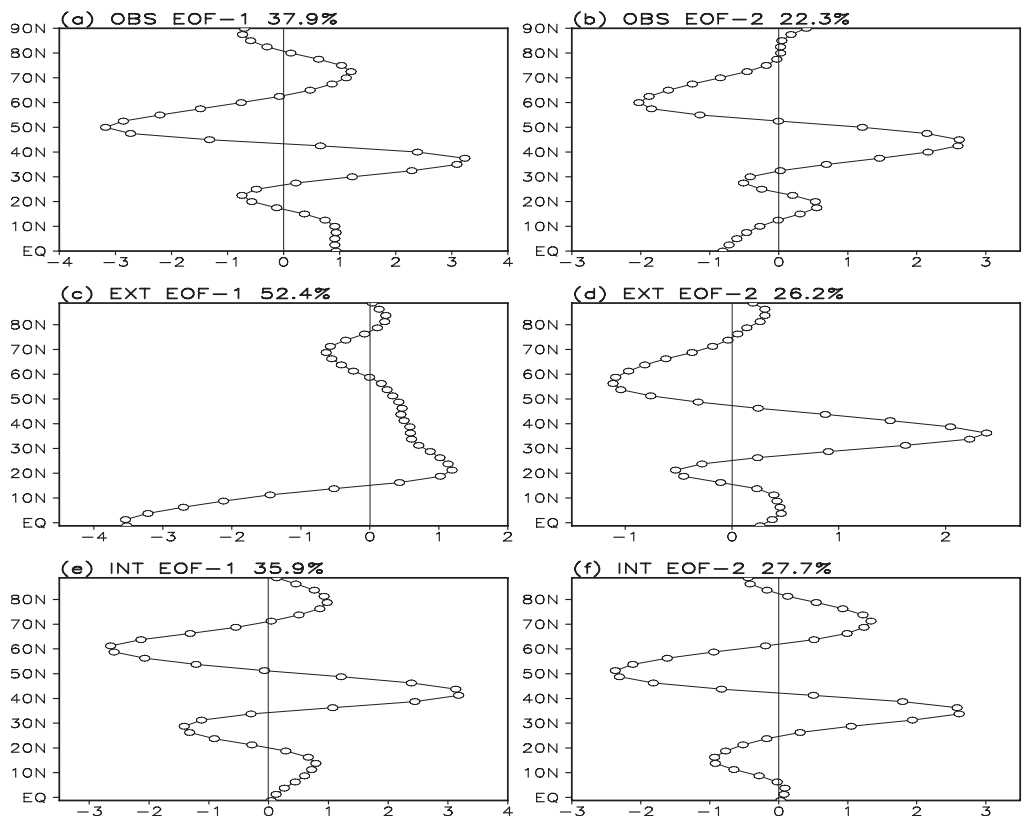

Fig. 8. Spatial structures of the first (left panels) and second (right panels) leading EOFs of JJAmean $200-\mathrm{hPa}$ zonal wind averaged over $120-150^{\circ} \mathrm{E}$, for observations (upper panels), external variability (middle panels) and internal variability (lower panels). Unit is arbitrary.

vations, model simulated external variability and internal variability, respectively. For observations, the first two leading EOFs in total explain over $60 \%$ of total variance. The observation EOF-1 shows a positive peak at $37.5^{\circ} \mathrm{N}$ and a negative peak at $50^{\circ} \mathrm{N}$, while it is close to zero at the axis (about $42^{\circ} \mathrm{N}$ ) of the EAJ (Fig. 8a). The values in the low and high latitudes are relatively much smaller. These features indicate that the observation EOF-1 is closely related to the meridional displacement of the EAJ. The observation EOF-2 shows a spatial distribution similar to the EOF-1, but its positive and negative peaks shift $5^{\circ}-10^{\circ}$ northwards (Fig. 8b). The most dominant positive peak concurs with the location of the EAJ axis, indicating that the observation EOF-2 is related to the variation in EAJ intensity. The present result also shows that these two dominant modes correspond respectively to the EAJ's meridional displacement and intensity variation, and is consistent with that in Lin and $\mathrm{Lu}$ (2005), who obtained their result according to a two-dimensional (longitude and latitude) EOF analysis at a narrow scope of latitudes.
Figures $8 \mathrm{c}$ and $8 \mathrm{~d}$ show the spatial structures of the first two leading EOFs of ensemble-mean $200-\mathrm{hPa}$ zonal wind averaged over $120-150^{\circ} \mathrm{E}$. The first mode explains $52.4 \%$ of total external variance, and the second one explains $26.2 \%$. The external EOF-1 is characterized by a sharp negative peak in the equator and relatively much smaller values off the equator, indicating that the external EOF-1 basically represents the mode of variations in the uppertropospheric zonal wind in the equator. This structure of external EOF-1 differs radically from that of observation EOF-1 (Fig. 8a), which can be reconfirmed by the low correlation between their principal components $(-0.28)$. As to the external EOF-2, it shows a positive peak at $37.5^{\circ} \mathrm{N}$ and a negative peak at $57.5^{\circ} \mathrm{N}$, as well as some minor peaks in the tropics and at the high latitudes (Fig. 8d). This distribution is more similar to that of the observation EOF-1 (Fig. 8a) than to that of the observation EOF-2 (Fig. 8b). Actually, the external PC-2 has a correlation coefficient of 0.48 with the observation PC-1 (significant at 90\% level), but a lower correlation coefficient of 0.28 with the observation PC-2. A further comparison of the external 
EOF-2 to the observation EOF-1 shows that for the former, the positive peak south to the EAJ axis is higher than the negative peak north to the EAJ axis, while for the latter, the two peaks have equivalent heights. This suggests that the external EOF-2 has a more weight in the relatively lower latitudes, which is consistent with the fact that the external mode has a tendency showing more signals in the low latitudes.

Similarly, an EOF analysis is performed by using 150 samples of the internal variability to illustrate the most dominant modes of internal variability in the upper-tropospheric zonal wind. The spatial structures of the first two leading modes of internal variability (Figs. 8e and $8 \mathrm{f}$ ) are similar to those of the observation EOF-2 and observation EOF-1, respectively, particularly around the EAJ axis. Thus, the internal EOF-1 is related to the variations in EAJ intensity, and the internal EOF-2 is related to the meridional displacement of EAJ. In the internal variability estimated by the model, the intensity variation of the EAJ exhibits a more dominant feature than the meridional displacement of the EAJ, while in observations the meridional displacement of the EAJ is more dominant. This difference between the internal variability and observations most likely results from the deficiency of the model in reproducing exactly the internal variability. It may also result from the contribution of the external variability, although the external variability is weaker than the internal variability over East Asia. We have examined the possibility of the sampling errors in the EOF estimation (North et al. 1982), and had a negative answer. We have analyzed the internal variability by using observational data through an approach as in Branstator (2002), and also analyzed the extended observational data during 46 years (1958-2003), and obtained very similar results.

We chose cases with extreme values of each time series of the principal components (Table 2 ), and performed composite analyses through an approach identical to that in the preceding section. In observations, the mode of EAJ's meridional displacement is associated with significant precipitation anomalies in East Asia and the tropical WNP (Fig. 9a), which is consistent with $\mathrm{Lu}$ (2004), who showed that a southward displacement of EAJ corresponds to more precipitation in East Asia and less precipita-
Table 2. Same as Table 1, but based on the EOFs of $200-\mathrm{hPa}$ zonal wind averaged over $120-150^{\circ} \mathrm{E}$, and only for the observation.

\begin{tabular}{l|ll|ll}
\hline & \multicolumn{2}{|c|}{+} & \multicolumn{2}{c}{-} \\
\hline Observation & 1991 & 1992 & 1990 & 1994 \\
PC-1 & 1993 & 1998 & 1997 & 1999 \\
\hline Observation & 1987 & 1990 & 1988 & 1989 \\
PC-2 & 1991 & 1995 & 1998 & 2000 \\
\hline
\end{tabular}

tion in the tropical WNP. This mode is associated with very weak and insignificant SST anomalies (Fig. 9c).

An intensified EAJ (or a positive observation PC-2) corresponds to more precipitation in the tropical WNP and less precipitation in the subtropical WNP (Fig. 9b). On the other hand, there are zonally elongated positive precipitation anomalies in the whole equatorial Pacific, which are possibly induced by the significant warmer SSTs in the equatorial central and eastern Pacific (Fig. 9d). However, the composite results, by using the extended period of observational data, show much weaker anomalies of precipitation in the equatorial Pacific and SSTs in the equatorial eastern Pacific (not shown).

The composite results based on the extended period (1958-2003 for circulation and SST, and 1979-2003 for precipitation) of observational data are basically consistent with those based on the 15-year data, except the changes clearly mentioned in the preceding and present sections. In this paper, we essentially compare the simulated results, only to robust observed results.

The internal EOF-1 is associated with significantly less precipitation in the subtropical WNP, and more precipitation in East Asia and the tropical WNP (Fig. 9e). The negative precipitation anomaly in the subtropical WNP is roughly consistent with that associated with the observation EOF-2 (Fig. 9b). The internal EOF-2 is associated with more precipitation in the Yangtze River and Huaihe River Basin in China, Southern Japan and subtropical WNP, and less precipitation in South China and the tropical WNP (Fig. 9f), which is roughly consistent with the composite results based on the observation EOF-1 (Fig. 9a). 

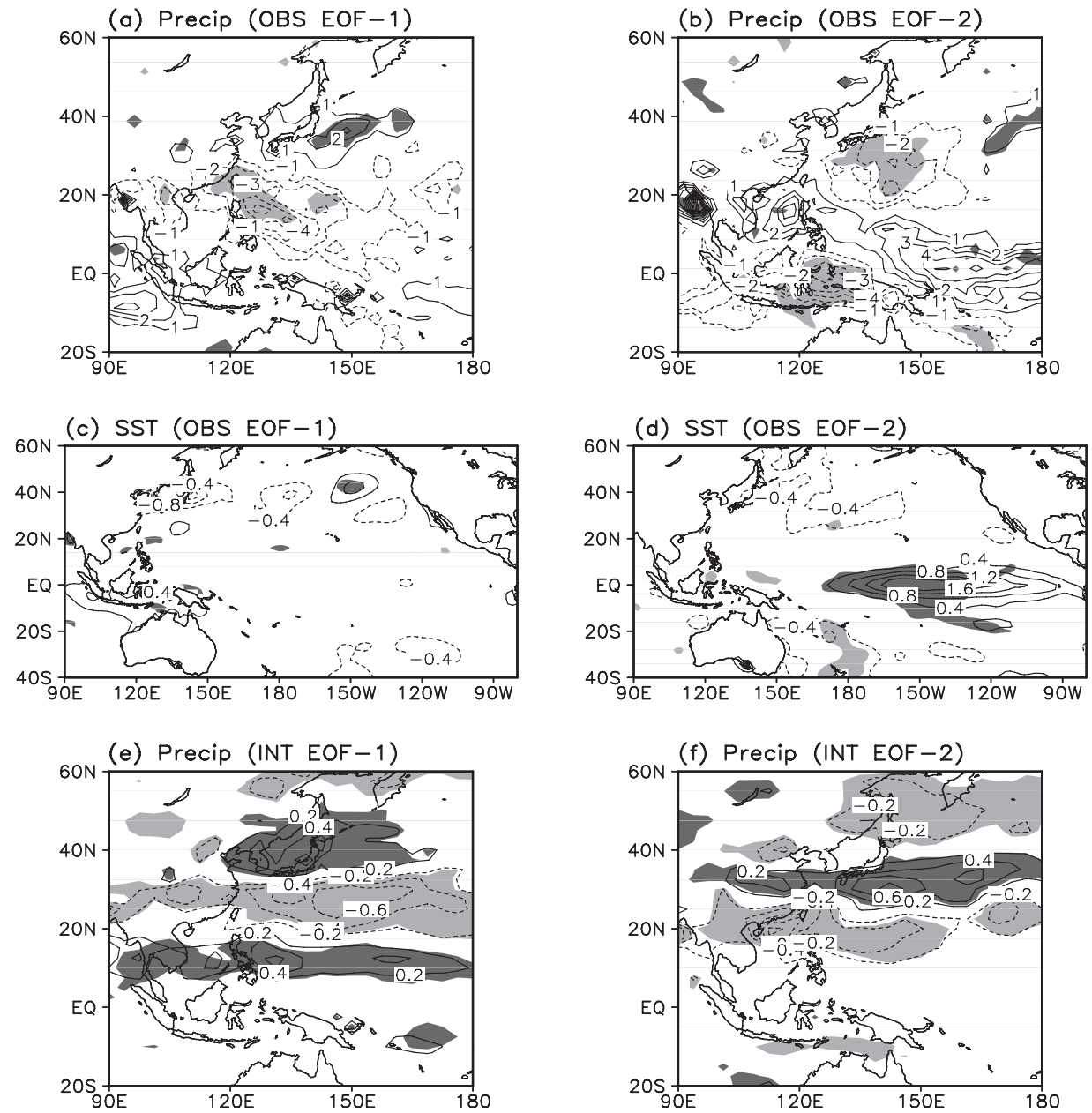

Fig. 9. (a-d) are same as Figs. $4 a-d$, but based on the EOF analysis on the 200-hPa zonal wind. (ef) are the precipitation regressed onto the normalized principal component of the first and second internal modes of $200-\mathrm{hPa}$ zonal wind, and the shading indicates the regions of $95 \%$ significance level based on the $F$-test.

\section{Conclusions and discussion}

In this study, we separated externally forced variability from internal variability in the year-to-year summer climatic anomalies in the WNP/EA sector through an ensemble of integrations by a model forced with the global observed SSTs, and examined the features of the external and internal variabilities. We focused on the first two dominant modes of circulation variations in the lower troposphere and upper troposphere, respectively, and investigated the precipitation and SST anomalies associated with these modes.

The internal variability of both precipitation and lower-tropospheric circulation is strong in the WNP. In the tropics, the internal variability of precipitation is comparable to the external variability, while that of circulation is much smaller than the external variability, indicating higher potential predictability in circulation than in precipitation there. However, the internal variability is larger than the external variability in East Asia, both for circulation and for precipitation.

The lower-tropospheric circulation anomaly over the WNP is dominated by the external variability. The external variability in the WNP/EA sector is mainly reflected by the first leading mode of lower-tropospheric zonal wind, 
and partially by the second mode. The first mode is characterized by a tropical teleconnection pattern. It is associated with an $850-\mathrm{hPa}$ anticyclonic (cyclonic) anomaly over the WNP, a seesaw pattern of precipitation between the western Pacific and maritime continent, and a negative (positive) SST anomaly in the equatorial eastern Pacific and a positive (negative) SST anomaly around the maritime continent. The second mode is characterized by a teleconnection of $850-\mathrm{hPa}$ zonal wind in the meridional direction, with zonally-oriented cells over the western Pacific, and associated with very weak SST anomalies. This second mode is more like a mode of the internal variability.

The variations of EAJ are dominated by the internal variability. Over East Asia, the internal variability is much stronger than the external variability, and comparable to the variability in observations. The first two leading internal modes of $200-\mathrm{hPa}$ zonal wind in the WNP/EA sector reflect the two dominant features of the variations of EAJ, i.e., intensity variation and meridional displacement, respectively. This is in consistent with the situation in observations, but in a reverse order. The first and second leading internal modes are associated with highly significant precipitation anomalies in the WNP/EA sector.

The strong internal variability leads to low predictability in the WNP/EA sector, and may be a crucial mechanism responsible for the current AGCMs have great difficulty to correctly simulate the interannual variation of summer rainfall in this region, particularly in East Asia, where the internal variability is more significant. The features of the internal variability in the WNP/EA sector should be further studied. Such studies would be helpful for the better understanding of the climatic variation and ocean-atmosphere coupling in this sector. Wang et al. (2004) suggested that oceanatmosphere coupling may play a crucial role in determining the climatic anomalies in the WNP. On the other hand, the intraseasonal variability (ISV) is also one of the dominant modes of the tropical WNP monsoon variability on a subseasonal time scale. Modelling studies of boreal summer ISV have been very limited, partly due to the difficulties in simulating both the mean monsoon and its variability (Sperber et al. 2000). The ability of atmospheric models to simulate the intraseasonal rainfall pattern has remained problematic. The results from a comparison study by Waliser et al. (2003) showed that models have difficulty in representing the tilted rain band and its propagation characteristics. It appears that air-sea interaction plays an important role in the simulation of summer ISV (e.g., Kemball-Cook and Wang 2001; Kemball-Cook et al. 2002; Rajendran et al. 2004; Fu and Wang 2004). Fu and Wang (2004) presented evidence that air-sea interaction results in more realistic boreal summer ISV. Compared to uncoupled simulation, the coupled model had 50\% more northward propogating events, and exhibits surface flux, convection, and SST feedbacks that resulted in a more realistic life cycle of the summer ISV. What is the relationship between ISV and interannual monsoon variability in summer? Is the realistic simulation of summer ISV a prerequisite for better mean monsoon climate and its interannual variability? These questions are required to be answered in the future.

The present results show that both external variability, and internal variability over East Asia are associated with precipitation anomalies in the tropics. Thus, the relation between the atmospheric convection over the tropical western North Pacific and climate anomalies in East Asia, which has been documented by previous observational studies (e.g., Nitta 1987; Tsuyuki and Kurihara 1989; Lu 2004; Wakabayashi and Kawamura 2004), can be established externally or internally. Separating externally forced variability and internal variability, may be helpful for a better understanding of the WNP convection-East Asian climate relationship.

The present study is mainly based on 15-year ensemble simulations and observational data. 15 years of data might not be adequately long for investigating the interannual variability, and thus a longer period of ensemble simulations is required to confirm the present results. However, the present results based on a longer period (1958-2003) of observational data are basically consistent with those based on the 15-year data, and we drew the present conclusions essentially based on the comparison between the robust observed results and simulated results.

In this study, we examined the outputs of 
only one model. Research by using other models is required to investigate whether the features of external and internal variability shown in this study are model dependent.

\section{Acknowledgments}

This study was supported by the Chinese Academy of Sciences (Grant No. KZCX3-SW221). The simulations were performed at the NCAS Centre for Global Atmospheric Modelling (CGAM), which is funded by the UK Natural Environment Research Council. We thank Dr. Masahiro Hosaka and two anonymous reviewers for their comments, which led to great improvement of our presentation.

\section{References}

Ailikun, B. and T. Yasunari, 2001: ENSO and Asian summer monsoon: Persistence and transitivity in the seasonal march. J. Meteor. Soc. Japan, 79, 145-159.

Branstator, G., 2002: Circumglobal teleconnections, the jet stream waveguide, and the North Atlantic oscillation. J. Climate, 15, 1893-1910.

Chou, C., J. Tu, and J. Yu, 2003: Interannual variability of the western North Pacific summer monsoon: Differences between ENSO and nonENSO years. J. Climate, 16, 2275-2287.

Cox, P.M., R.A. Betts, C.B. Bunton, R.L.H. Essery, P.R. Rowntree, and J. Smith, 1999: The impact of new land surface physics on the GCM simulation of climate and climate sensitivity. Climate Dyn., 15, 183-203.

Enomoto, T., 2004: Interannual variability of the Bonin high associated with the propagation of Rossby waves along the Asian Jet. J. Meteor. Soc. Japan, 82, 1019-1034.

Fu, X. and B. Wang, 2004: Differences of boreal summer intraseasonal oscillations simulated in an atmosphere-ocean coupled model and an atmosphere-only model. J. Climate, 17, 12631271.

Goswami, B.N., 1998: Interannual variations of Indian summer monsoon in a GCM: External conditions versus internal feedbacks. J. Climate, 11, 501-522.

Harzallah, A. and R. Sadourny, 1995: Internal versus SST-forced atmospheric variability as simulated by an atmospheric general circulation model. J. Climate, 8, 474-495.

Huang, R. and Y. Wu, 1989: The influence of ENSO on the summer climate change in China and its mechanism. Adv. Atmos. Sci., 6, 21-32.

Kalnay, E. and Coauthors, 1996: The NCEP-NCAR 40-year reanalysis project. Bull. Amer. Meteor. Soc., 77, 437-471.
Kang, I.-S., J.-Y. Lee, and C.-K. Park, 2004: Potential predictability of summer mean precipitation in a dynamical seasonal prediction system with systematic error correction. J. Climate, 17, 834-844.

Kemball-Cook, S. and B. Wang, 2001: Equatorial waves and air-sea interaction in the boreal summer intraseasonal oscillation. J. Climate, 14, 2923-2942.

Kemball-Cook, S., B. Wang, and X. Fu, 2002: Simulation of the intraseasonal oscillation in the ECHAM4 model: The impact of coupling with an ocean model. J. Atmos. Sci., 59, 1433-1453.

Krishnan, R. and M. Sugi, 2001: Baiu rainfall variability and associated monsoon teleconnections. J. Meteor. Soc. Japan, 79, 851-860.

Lau, K.-M., K.-M. Kim, and S. Yang, 2000: Dynamical and boundary forcing characteristics of regional components of the Asian summer monsoon. J. Climate, 13, 2461-2482.

Lin, Z. and R. Lu, 2005: Interannual meridional displacement of the East Asian up-tropospheric jet stream in summer. Adv. Atmos. Sci., 22, 199-211.

Liang, X.-Z. and W.-C. Wang, 1998: Associations between China monsoon rainfall and tropospheric jets. Quart. J. Roy. Meteor. Soc., 124, 2597-2623.

Lu, R., 2001: Interannual variability of the summertime North Pacific subtropical high and its relation to atmospheric convection over the warm pool. J. Meteor. Soc. Japan, 79, 771-783. and B. Dong, 2001: Westward extension of North Pacific subtropical high in summer. $J$. Meteor. Soc. Japan, 79, 1229-1241.

— 2002: Precursory SST anomalies associated with the convection over the western Pacific warm pool. Chinese Science Bulletin, 47, 696699.

— , J.-H. Oh, and B.-J. Kim, 2002: A teleconnection pattern in upper-level meridional wind over the North African and Eurasian continent in summer. Tellus, 54A, 44-55.

- 2004: Associations among the components of the East Asian summer monsoon system in the meridional direction. J. Meteor. Soc. Japan, 82, 155-165.

Nitta, T., 1987: Convective activities in the tropical western Pacific and their impacts on the northern hemisphere summer circulation. J. Meteor. Soc. Japan, 65, 373-390.

North, G.R., T.L. Bell, R.F. Cahalan, and F.J. Moeng, 1982: Sampling errors in the estimation of empirical orthogonal functions. Mon. Wea. Rev., 110, 699-706.

Pope, V.D., M.L. Gallani, P.R. Rowntree, and R.A. Stratton, 2000: The impact of new physical pa- 
rameterizations in the Hadley Centre climate model-HadAM3. Climate Dyn., 16, 123-146.

Rajendran, K., A. Kitoh, and S. Yukimoto, 2004: South and East Asian summer monsoon climate and variation in the MRI coupled model (MRI-CGCM2). J. Climate, 17, 763-782.

Reynolds, R.W., N. Rayner, T. Smith, D. Stokes, and W. Wang, 2002: An improved in situ and satellite SST analysis for climate. J. Climate, 15, 1609-1625.

Rowell, D.P., C.K. Folland, K. Maskell, and M.N. Ward, 1995: Variability of summer rainfall over tropical north Africa (1906-92): Observations and modeling. Quart. J. Roy. Meteor. Soc., 121, 669-704.

Sato, N. and M. Takahashi, 2003: Formation mechanism of vorticity anomalies on the subtropical jet in the midsummer Northern Hemisphere. Theoretical and Applied Mechanics Japan, 52, 109-115.

Smith, T.M. and R.W. Reynolds, 2004: Improved Extended Reconstruction of SST (1854-1997). J. Climate, 17, 2466-2477.

Sperber, K.R., J.M. Slingo, and H. Annamalai, 2000: Predictability and the relationship between subseasonal and interannual variability during the Asian summer monsoon. Quart. J. Roy. Meteor. Soc., 126, 2547-2574.

Tanaka, M., 1997: Interannual and interdecadal variations of the western North Pacific monsoon and Baiu rainfall and their relationship to the ENSO cycles. J. Meteor. Soc. Japan, $\mathbf{7 5}$, 1109-1123.

Tsuyuki, T. and K. Kurihara, 1989: Impact of convective activity in the western tropical Pacific on the East Asian summer circulation. J. Meteor. Soc. Japan, 67, 231-247.

Waliser, D.E. and coauthors, 2003: AGCM simulations of intraseasonal variability associated with the Asian summer monsoon. Climate Dyn., 21, 423-446.

Wakabayashi, S. and R. Kawamura, 2004: Extrac- tion of major teleconnection patterns possibly associated with the anomalous summer climate in Japan. J. Meteor. Soc. Japan, 82, 1577-1588.

Wang, B., R. Wu, and X. Fu, 2000: Pacific-East Asian teleconnection: How does ENSO affect East Asian climate? J. Climate, 13, 1517-1536. , — , and K.-M. Lau, 2001: Interannual variability of the Asian summer monsoon: Contrasts between the Indian and the western North Pacific-East Asian monsoons. J. Climate, 14, 4073-4090. - and Q. Zhang, 2002: Pacific-East Asian teleconnection. Part II: How the Philippine Sea anticyclone established during development of El Niño. J. Climate, 15, 3252-3265.

, I.-S. Kang, and J.-Y. Lee, 2004: Ensemble simulations of Asian-Australian monsoon variability by 11 AGCMs. J. Climate, 17, 803-818.

Wang, H., F. Xue, and X. Bi, 1997: The interannual variability and predictability of a global climate model. Adv. Atmos. Sci., 14, 554-562.

Wu, R. and B. Wang, 2002: A contrast of the East Asian summer monsoon-ENSO relationship between 1962-77 and 1978-93. J. Climate, 15, 3266-3279.

and - 2000: Interannual variability of summer monsoon onset over the western North Pacific and the underlying processes. $J$. Climate, 13, 2483-2501.

Xie, P. and P.A. Arkin, 1997: Global precipitation: A 17-year monthly analysis based on gauge observations, satellite estimates, and numerical outputs. Bull. Amer. Meteor. Soc., 78, 25392558.

Zhang, R., A. Sumi, and M. Kimoto, 1996: Impact of El Niño on the East Asian monsoon: A diagnosis study of the '86/87 and '91/92 events. J. Meteor. Soc. Japan, 74, 49-62. -, and 1999: A diagnosis study of the impact of El Niño on the precipitation in China. Adv. Atmos. Sci., 16, 229-241. 